\title{
Scale effects in sliding friction: An experimental study
}

\section{Peter J. Blau}

Metals and Ceramics Division

Oak Ridge National Laboratory

P. O. Box 2008

Oak Ridge, TN 37831-6063 USA

(615) 574-5377, FAX (615) 574-4913

\section{DRAFT COPY FOR REVIEW}

24 July 1991

\section{MASTER}

Prepared for the NATO Advanced Study Institute on Fundamentals of Friction

Braunlage, Germany 29 July - 9 August 1991 DISTRIBUTION OF THIS DOCUMENT IS UNLIMITED 


\section{ABSTRACT}

Solid friction is considered by some to be a fundamental property of two contacting materials, while others consider it to be a property of the larger tribosystem in which the materials are contained. A set of sliding friction experiments were designed to investigate the hypothesis that the unlubricated sliding friction between two materials is indeed a tribosystems-related property and that the relative influence of the materials properties or those of the machine on friction varies from one situation to another. Three tribometers were used: a friction microprobe (FMP), a typical laboratory-scale reciprocating pin-on-flat device, and a heavy-duty commercial wear tester. The slider material was stainless steel (AISI 44OC) and the flat specimen material was an ordered alloy of $\mathrm{Ni}_{3} \mathrm{Al}$ (IC-50). Sphere-on-flat geometry was used at ambient conditions and at normal forces ranging from $0.01 \mathrm{~N}$ to $100 \mathrm{~N}$ and average sliding velocities of 0.01 to $100.0 \mathrm{~mm} / \mathrm{s}$. The nominal, steady-state sliding friction coefficient tended to decrease with increases in normal force for each of the three tribometers, and the steady state value of sliding friction tended to increase as the mass of the machine increased. The variation of the friction force during sliding was also a characteristic of the test system. These studies provide further support to the idea that the friction of both laboratory-scale and engineering tribosystems should be treated as a parameter which may take on a range of characteristic values and not conceived as having a single, unique value for each material pair.

\section{INTRODUCTION}

The development of fundamental models for friction has depended on the viewpoint of the individual investigator and is largely based on his or her scientific or technical training and accumulated experience. It is also based upon the concept of what a tribosurface is, how it reacts, and what simplifying or boundary conditions the modeler chooses to impose. A mechanics-oriented investigator Is likely to lump materials properties into such bulk properties as shear strength and elastic modulus, a materials scientist may often opt for qualitative or descriptive models which include dislocation interactions, grain sizes, and crystal structure-related parameters, and a chemist or surface physicist may impose chemical or atomic bonding characteristics.

As the foregoing indicates, techno-cultural differences are significant in a field as broad as tribology. Individuals with a mechanical engineering or mechanics background have no trouble recognizing the importance of machine stiffness or vibrations in frictional behavior, but only recently, have materials scientists come to acknowledge the possibility that friction cannot be modelled exclusively in terms of materials deformation and fracture. Those who conduct atomic-scale friction studies and take surface physics approaches may take the mechanics of machine fixtures into account during the construction of their instruments, but might not always consider such effects in interpreting 
experimental results. The question then arises: At what scale, and under what conditions do the characteristics of the tribometer begin to affect frictional behavior? It is contended that the tribometer influences frictional behavior no matter what the size of the contact; however, that this influence may vary greatly in its relative effect on friction compared with surface properties.

Considering the myriad possible phenomena which can occur simultaneously and at various size scales during solid sliding, all approaches to modeling friction of the general case are incomplete. It - is true, however, that in specific cases of very wellcharacterized and controlled tribosystems, a large number of the possible influences on friction can be considered inconsequential, and reasonably accurate, semi-empirical models can be developed.

our evolving understanding of physical surfaces parallels the history of instrumentation available to measure and image surfaces. surface concepts based mainly on profiling techniques may produce quite different friction models than concepts based on microscopy of contact damage at various magnifications or of etched crosssections below contact surfaces. Figure 1 illustrates typical dimensions of surface-related features: from atoms to the size of typical "pin-on-disk" wear tests. As microscopy and surface imaging techniques evolve, an evolution of friction models is likely to occur as well.

An excellent review of classical concepts of friction was published by Bowden [1], and more recently, Rabinowicz [2] has addressed the statistical nature of friction. Recent work by the present author on scale effects in friction [3] suggests that successful, predictive models for friction must, in general, consider systems characteristics as well as materials properties, and that theorists and modelers should strive to define the boundaries and distributions of expected values rather than to derive a single value for friction. Particularly in the case of running-in, a system can pass through a number of frictional states [4], and other transitions are also possible [5]. Figure 2 indicates that the contributions of materials and topographic factors to interfacial friction can change based on contact pressure (load) and time of sliding. It is such transitional behavior that greatly complicates our gaining a clear understanding.

Sliding friction experiments were conducted to graphicallydemonstrate that the unlubricated sliding friction between two materials is a tribosystems-related property and that the degree to which the materials or the machine will affect the measured friction is also system-dependent.

\section{EXPERIMENTAL DETAILS}

Three machines were used in this investigation: an ORNLdeveloped, low-load, friction microprobe (FMP) [6], a typical laboratory-scale reciprocating pin-on-flat device (P-O-F), and a heavier, commercial wear tester: Cameron-Plint TE-77 (C-P). 
A schematic illustration of the friction microprobe is given in Figure 3. It consists of a small "boat" suspended between two elastic webs. A stationary, low mass stylus containing a $1.0 \mathrm{~mm}$ diameter sphere of stainless steel AISI $440 \mathrm{C}$ was the slider. As the computer-controllta, position-encoded traverse stage moves, the slider friction restrains the stage and deflects the supporting webs. This deflection is measured by a capacitive transducer system. By calibrating the force and deflection characteristics of the webs, the instantaneous stylus position with respect to the flat specimen, as well as the tangential (friction) force, can be determined. In the current experiments, the stage traverse velocity was set at $10.0 \mu \mathrm{m} / \mathrm{s}$ and the track length was $100 \mu \mathrm{m}$. Normal forces ranged from 9.8 to $98.1 \mathrm{mN}$. Friction force readings were taken when the stylus friction had become relatively level so that the sliding velocity of the stylus matched that of the traversing stage. All tests were performed in air.

Figure 4 shows a schematic diagram of the pin-on-flat reciprocating wear machine. The "pin" specimen was a $9.52 \mathrm{~mm}$ diameter bearing ball of AISI $440 \mathrm{C}$ stainless steel. Metallographically-etched cross-sections of both the $1.0 \mathrm{~mm}$ diameter and $9.52 \mathrm{~mm}$ diameter balls revealed similar microstructures consisting of fine carbides dispersed in a ferrous matrix. Normal forces ranged from $0.98 \mathrm{~N}$ to $15.0 \mathrm{~N}$. The reciprocating velocity averaged $0.1 \mathrm{~m} / \mathrm{s}$ over a $5.0 \mathrm{~mm}$ track length. The commercial wear testing machine (C-P) used the same diameter ball as the pin-on-flat tester, the same track length, and the same average velocity. The normal force ranged from 10.0 to $100.0 \mathrm{~N}$. Table 1 summarizes the various tests performed in the course of this study.

Table 1.

\section{SUMMARY OF TESTING CONDITIONS}

Testing Variable

slider diameter ( $\mathrm{mm})$

stroke length ( $\mathrm{mm})$

average velocity $(\mathrm{mm} / \mathrm{s})$

duration of test (full cycles)

rinimum normal force (N)

maximum normal force (N)

testing environment

relative humidity range

testing temperature

tests per condition

\begin{tabular}{c} 
FMP \\
\hline 1.0 \\
\hline 0.1 \\
0.01 \\
10. \\
0.01 \\
0.98 \\
air \\
$50 \pm 15$ \\
room T \\
3
\end{tabular}

\begin{tabular}{c}
$\mathrm{P}-\mathrm{O}-\mathrm{F}$ \\
\hline 9.52 \\
10.0 \\
100.0 \\
1000. \\
1.0 \\
15.0 \\
air \\
$55 \pm 10$ \\
room $\mathrm{T}$ \\
3
\end{tabular}

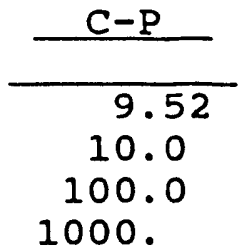

10.0

100.0

air

$65 \pm 12$

room $T$

The flat specimen material was a mirror-polished surface of $\mathrm{Ni}_{3} \mathrm{Al}$ alloy IC-50 of nominal composition: 11.3 wto $\mathrm{Al}, 0.6$ wto $\mathrm{Zr}$, 0.02 wt $z$ B and the balance Ni. It was a single-phase, 
polycrystalline material produced by strip rolling with a grain size of about 10-20 $\mathrm{mm}$. The tribological behavior of this material against a variety of slider materials, unlubricated and lubricated, was recently reported elsewhere [7]. The surfaces of all contacting materials were swabbed with acetone and ethanol within ten minutes of testing. Unworn surfaces were used for each test.

\section{RESULTB}

The quantities defining the friction coefficients reported here are given in Fig. 5. The nominal values are not calculated from digital data, but rather estimated from analog friction traces. The friction coefficient variability represents the typical maximum and minimum value observed during a single pass of the slider during the steady state period.

The nominal friction coefficient is plotted as a function of normal force for all three machines in Fig. 6 (a)-(c). All three machines displayed a trend of decreasing friction coefficient with increasing load.

The variation in friction coefficient is plotted against normal force in Fig. 7 (a)-(c). The FMP and the commercial heavyload machine both exhibited a decreasing variation with normal force, but the mid-range, pin-on-flat machine exhibited a wide scatter band of frictional variability with no obvious trends.

The relationship between the apparent contact area and the variation in friction coefficient during a given run was examined for both the mid-range machine and the heavy-load machine. Wear tracks were not discernable on the FMP specimens. Fig's. 8 were plotted assuming that the nominal contact area is proportional to the track width squared. No relationship is observed for the midrange, pin-on-flat tribometer data. Except for one datum, the variation in friction coefficient for the heavy-load machine tended to correlate with the square of the track width in a non-linear manner. The reason for the behavior of the outlying point is not known.

\section{DISCUSSION}

The friction coefficient declined as a function of rising normal load for all three sets of tests. It is therefore concluded that this behavior is independent of the testing machine. It may represent a change in mechanisms responsible for the friction force as the magnitude and modes for accommodating the imposed shear stresses changed.

At the lightest normal forces (FMP), friction was likely to have been governed by the shear of thin ambient oxide films and atmospheric contaminants such as adsorbed hydrocarbons. The dominant oxide on $\mathrm{Ni}_{3} \mathrm{Al}$ under ambient conditions is $\mathrm{NiO}$ [8]. As the normal force was increased, contributions from plastic shear deformation of the sliding materials increased. Wear tracks un the 
pin-on-disk machine and on the commercial machine showed extensive evidence for severe metallic wear behavior. Thus, there was a major contribution from plowing and asperity interlocking. No evidence for wear was observed on the ball or flat in the FMP case.

The variation in friction coefficient is affected by the stiffness of the testing machine. The more compliant the machine, the more likely that relatively small frictional perturbations will be amplified by the machine and that they will persist long enough to be detected by the force-measuring system. The natural frequency of the FMP and the pin-on-flat machine were similar (about 24-26 Hz), therefore the greater frictional variation of the latter machine cannot be explained in terms of its difference in natural frequency. The pin-on-flat machine (Fig. 4) measured friction by a relatively compliant strip of strain-gaged steel. The FMP, with its twin webs and sensitive capacitive displacement system, is relatively stiff in comparison, as is the commercial machine which uses a stiff, piezoelectric load cell. The compliance of the pin-on-flat machine therefore tended to mask the effect of lowering frictional variation with increasing load and track width.

A compliant system experiences a relatively large off-set of the sliding contact from the friction force. Thus the location of the contact area is a function of the friction force. Frictional variations may produce large accelerations or decelerations in the localized contact zone and the microscopic sliding velocity at any instant will be much different than that imposed macroscopically. In a stiff system, the off-set in the position of the contact is not so significant and the sliding velocity remains more constant.

For the FMP experiments, Hertz stress calculations predicted an elastic contact diameter of about $2.5 \mu \mathrm{m}$ for the $9.8 \mathrm{mN}$ load. This is within the size range of a carbide particles observed on polished sections of the AISI $440 \mathrm{C}$ steel sliders. The carbides were spaced 2.0-5.0 $\mathrm{mm}$ apart. Therefore, it is likely that one or more carbides were present in the contact area and that the proportion of carbide to matrix might vary significantly from on run to another. Despite the relatively large potential for the effect of sliding differences between carbides and matrix in the steel, the variation of the friction coefficient within each FMP run was small. From this, one concludes either that the friction was governed more by the shear of surface films on the IC-50 alloy than the ball material, or that the carbides protruded slightly from the ferrous matrix on the ball, assuring that it was always carbide sliding on IC-50. In any case, it was not possible by optical microscopy (up to $420 \mathrm{x}$ ) to detect evidence of sliding damage on either the ball tip or the flat material after the tests, indicating that very fine-scale processes were dominating the frictional behavior.

In summary, scale effects are important for understanding the frictional behavior of specific tribosystems and for developing the proper approach for modeling friction. The relative contributions 
to the friction force and its variation may change with contact pressure and with time. In the present experiments, the frictional hehavior for the same pair of materials was strongly influenced by the contact size and by the testing machine. The small contact sizes and pressures developed by the FMP permitted the influences of fine-scale phenomena to dominate, but the larger contact pressures and nominal friction coefficients of the other two machines exhibited the effects of material deformation and surface roughening on friction.

\section{CONCLUSIONS}

A series of sliding friction experiments were conducted to examine the hypothesis that the friction between two materials can be different depending upon the way that they are tested or used. Current findings were:

1. In all three machines, the nominal friction coefficient decreased as the normal force increased.

2. The friction coefficient varied in magnitude and variation between one machine and another.

3. The higher the testing machine, the higher the nominal friction coefficient tended to be.

4. The variations in friction force were a consequence of the system stiffness. This represents a practical challenge for characterizing and modeling the frictional behavior of practical engineering tribosystems.

5. The nominal friction coefficient and its variation at steady state are both materials and system variables, and the extent that each contributes to the macroscopic friction force characteristics must be analyzed on a case-by-case basis.

A better definition for the sliding friction characteristics of real tribosystems is needed. For ineffectively lubricated or unlubricated sliding, a single, nominal value may be useful only approximately, but may be misleading in the long run. The definition should be written in such a way that the characteristic fluctuations in friction for the system are taken into account. Embedded within the observed variation in friction is the mechanical feedback between the localized, material-induced stimulus and the response of the machine to that stimulus. A hierarchy of scale-effects-based friction models should be developed depending on the microscopic processes dominating the macroscopic frictional response and the type of system under consideration.

\section{ACRNOWLEDGEMENTS}

The assistance of Ms. Fang-Lei Wang, Princeton University, with these experiments is appreciated, and the continuing support 
of the Office of Transportation Materials, Tribology Program, U.S. Department of Energy, under contract DE-AC05-840R21400 with Martin Marietta Energy Systems, Inc. is also acknowledged.

\title{
References
}

1) F. P. Bowden, "A Review of the Friction of Solids, "Wear, Vol. 1, pp. 333-346 (1957/58).

2) E. Rabinowicz, "Investigation of Size Effects in sliding by Means of Statistical Techniques," Proc. of the Conf. on Lubr. and Wear, Instit. of Mech. Engr., London, pp. 276-280 (1957).

3) P. J. Blau, "Scale Effects in steady state Friction," Trib. Trans., Vol. 34, pp. 335-342 (1991).

4) P. J. Blau, "Running-in: Art or Engineering?", J. of Mater. Engrg., Vol. 13, pp. 47-53 (1991).

5) P. J. Blau, Friction and Wear Transitions of Materials, Noyes Publications, Park Ridge, NJ (1989).

6) P. J. Blau, "Friction Microprobe Studies of Composite Surfaces," in The Tribology of Composite Materials, ed. P. K. Rohatgi, P. J. Blau, and C. S. Yust, ASM International, Materials Park, Ohio, pp. 59-68 (1990).

7) P. J. Blau and C. E. DeVore, "sliding friction and wear behaviour of several nickel aluminide alloys under dry and lubricated conditions," Trib. Int'l,, Vol. 23 (4), pp. 226-234 (1990).

8) G. C. Wood and B. Chattopadhay, "Transient oxidation of Nibase Alloys," Corros. Sci., Vol. 10, p. 271 (1970).

\section{DISCLAIMER}

\begin{abstract}
This repurt was prepared as an account of work sponsored by an agency of the United States Government. Neither the United States Government nor any agency thereof, nor any of their employees, makes any warranty, express or implied, or assumes any legal liability or responsibility for the accuracy, completeness, or usefulness of any information, apparatus, product, or process disclosed, or represents that its use would not infringe privately owned rights. Reference herein to any specific commercial product, process, or service by trade name, trademark, manufacturer, or otherwise does not necessarily constitute or imply its endorsement, recommendation, or :avoring by the United States Government or any agency thereof. The views and opinions of authors expressed herein do not necessarily state or reflect those of the United States Government or any agency thereof.
\end{abstract}


Figure captions:

1) Schematic illustration of the size scales for various phenomena associated with tribology.

2) The relative contributions of various factors to friction can change not only with contact pressure but also with the duration of contact.

3) Diagram of the friction microprobe (FMP). The unit is contained in a plastic box to shield it against air currents, and the base stands on an air-supported anti-vibration table.

4) Diagram of the pin-on-disk machine.

5) Definition of the nominal friction coefficient and the range in friction coefficients.

6) Nominal friction force as a function of the normal force for (a) the friction microprobe, (b) the pin-on-flat laboratory tribometer, and (c) the Cameron-Plint TE-77 commercial wear testing machine. Each datum represents a single run.

7) Variation in the "steady state" friction force for runs on three different machines: (a) the friction microprobe, (b) the pin-onflat laboratory tribometer, and (c) the Cameron-Plint TE-77 commercial wear testing machine. Each datum represents a single run.

8) Relationship between the variation in the friction coefficient and the square of the wear track width, a quantity proportional to the apparent area of contact: (a) the pin-on-flat laboratory tribometer, and (b) the Cameron-Plint TE-77 commercial wear testing machine. Each datum represents a single run. 
ORNL-DWG 91-12559

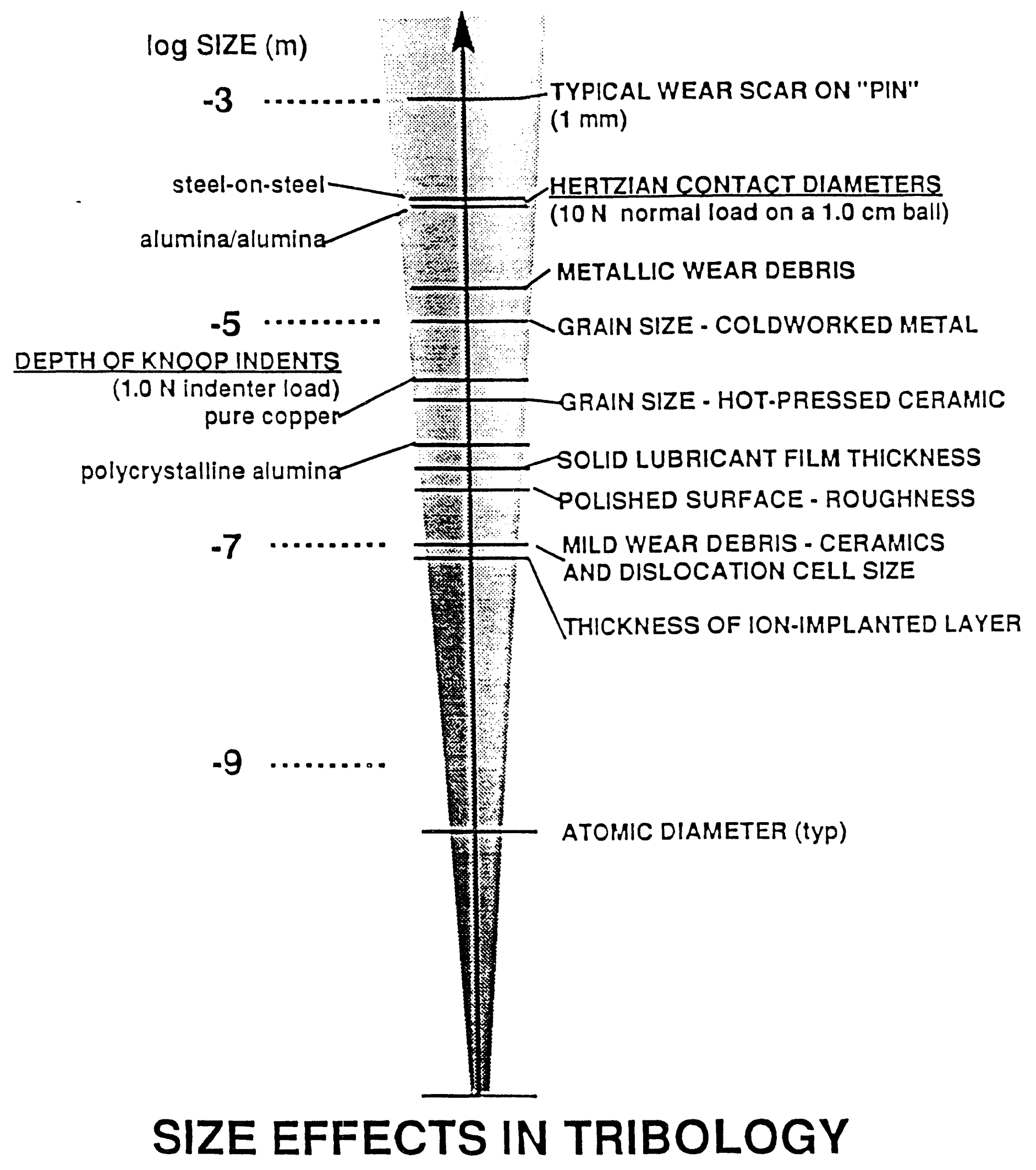

Fig. 1 


\section{THE RELATIVE CONTRIBUTIONS TO FRICTION DEPEND ON BOTH THE IMPOSED CONDITIONS AND ON TIME}

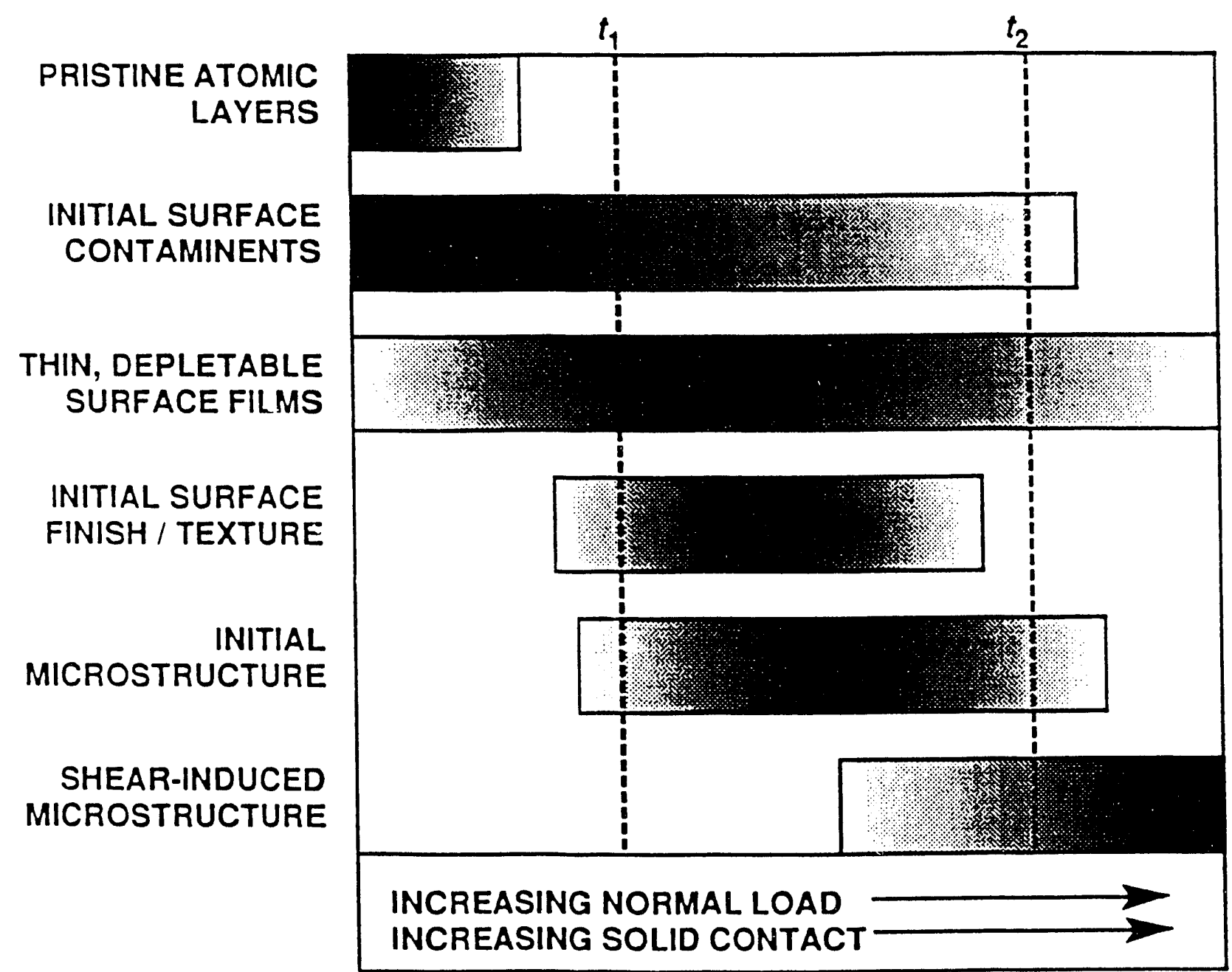

Fig 2 


\section{GENERAL ARRANGEMIENT OF THE} FRICTION MICROPROBE

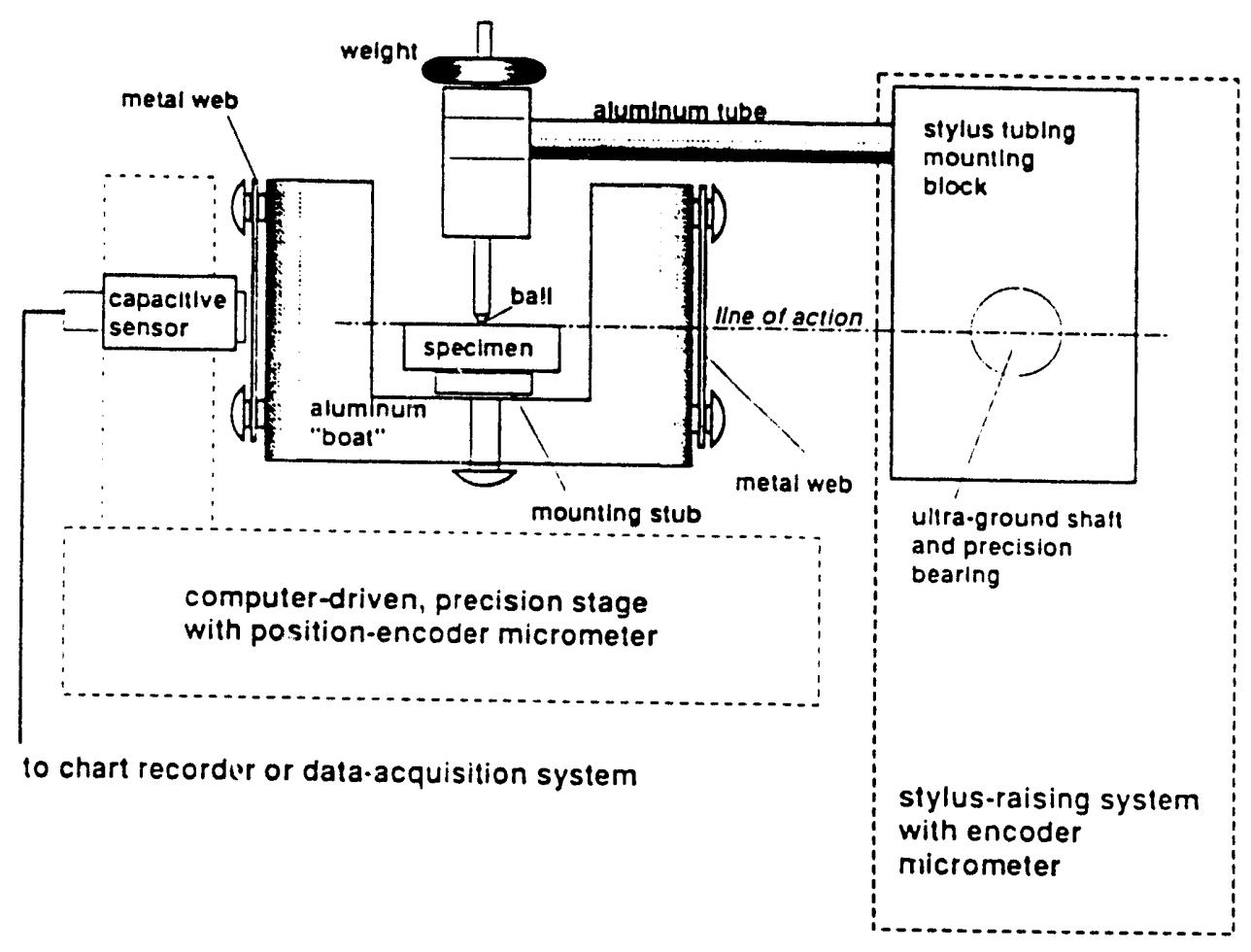

Fig 3 
Fig 4

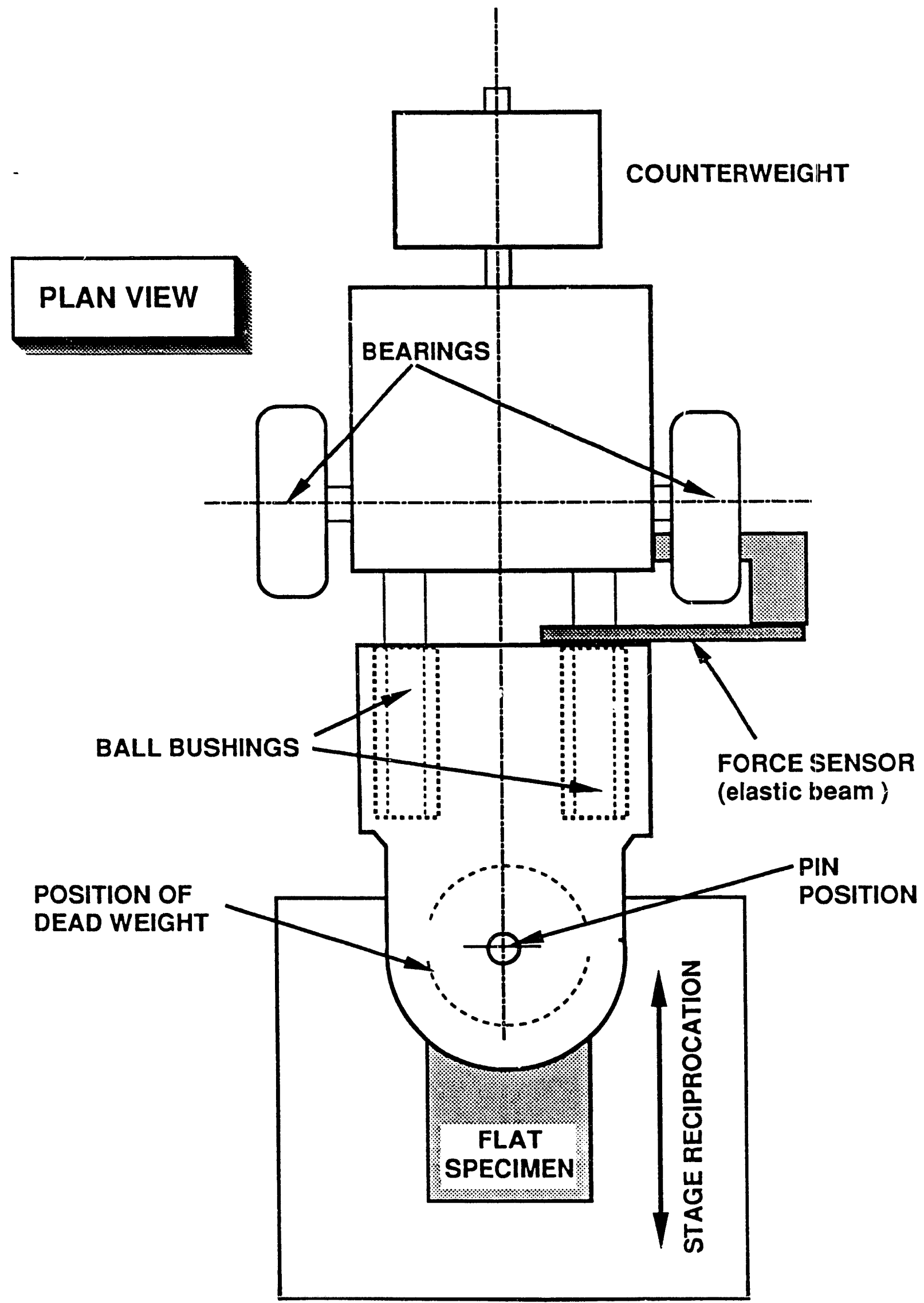




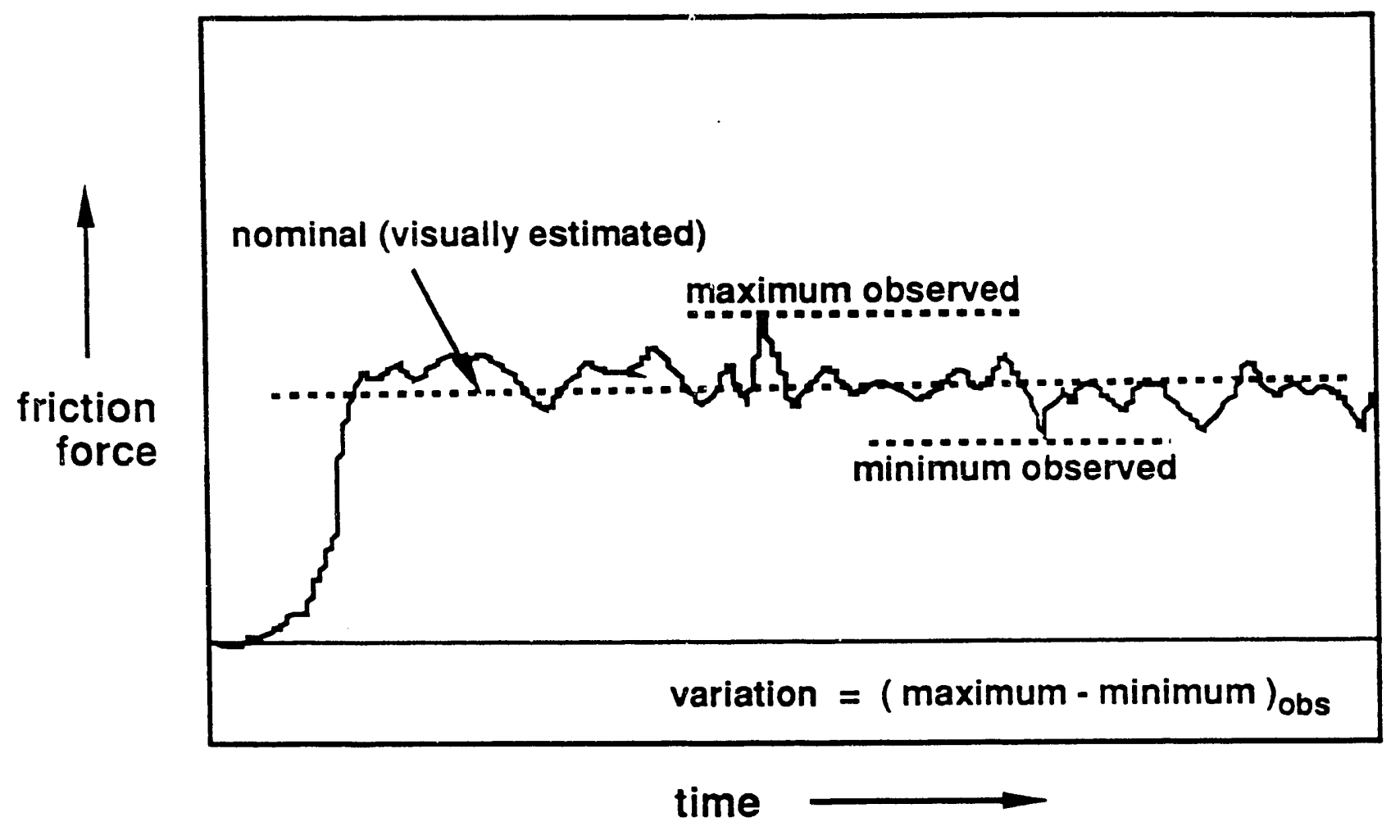

Fig 5 
ORNL-DWG 91-12561
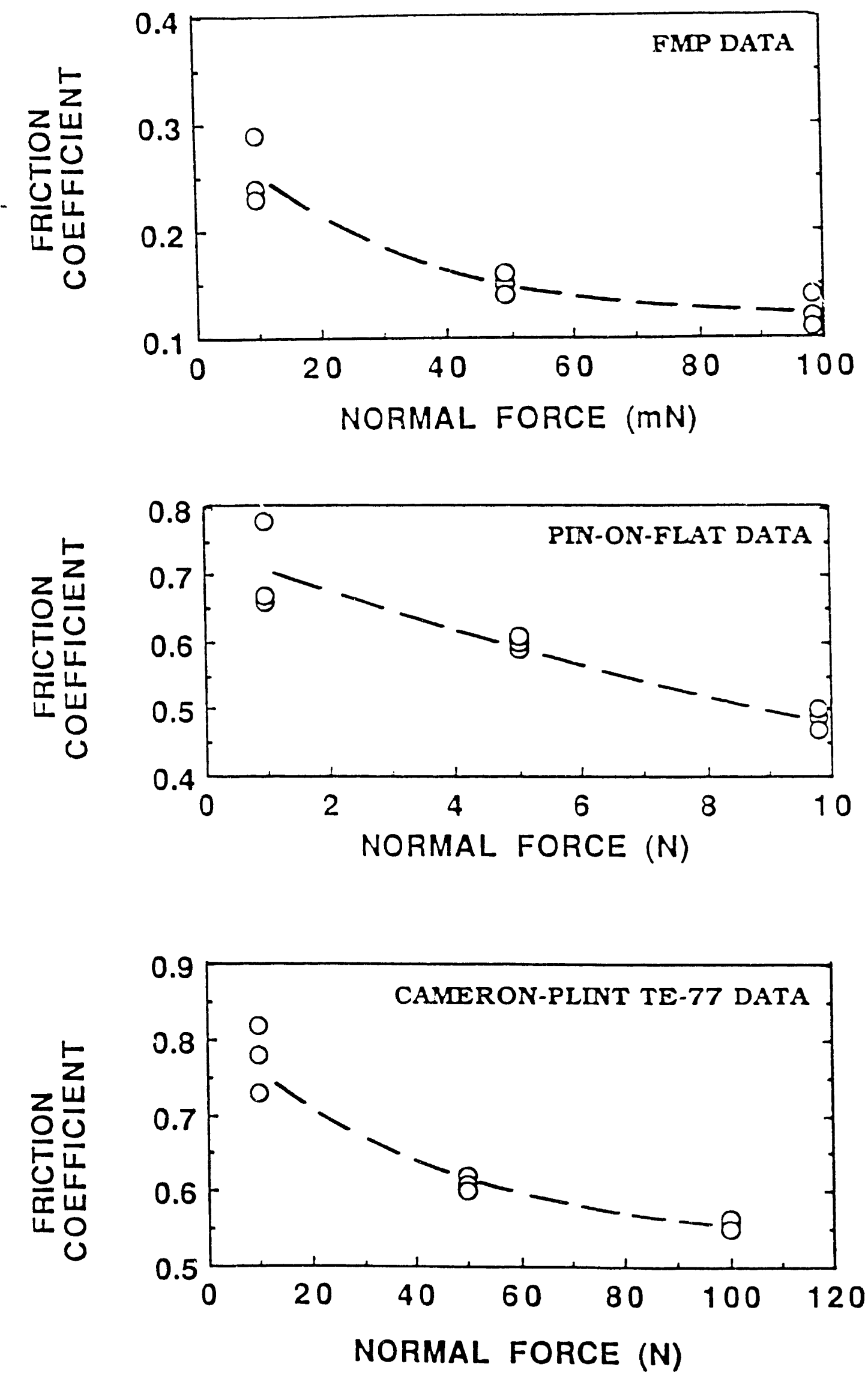

Fig 6 


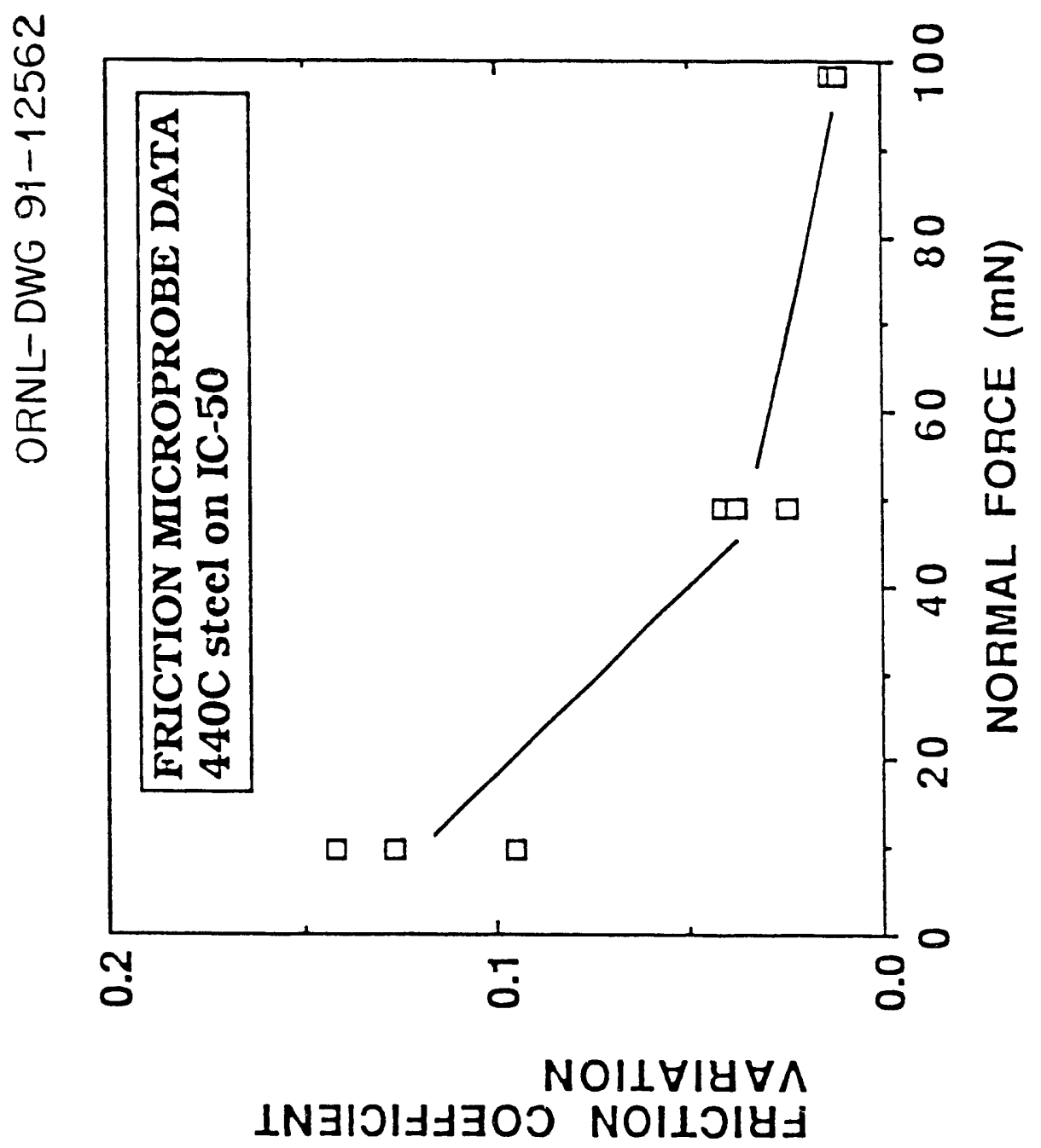

Fig 7(a) 


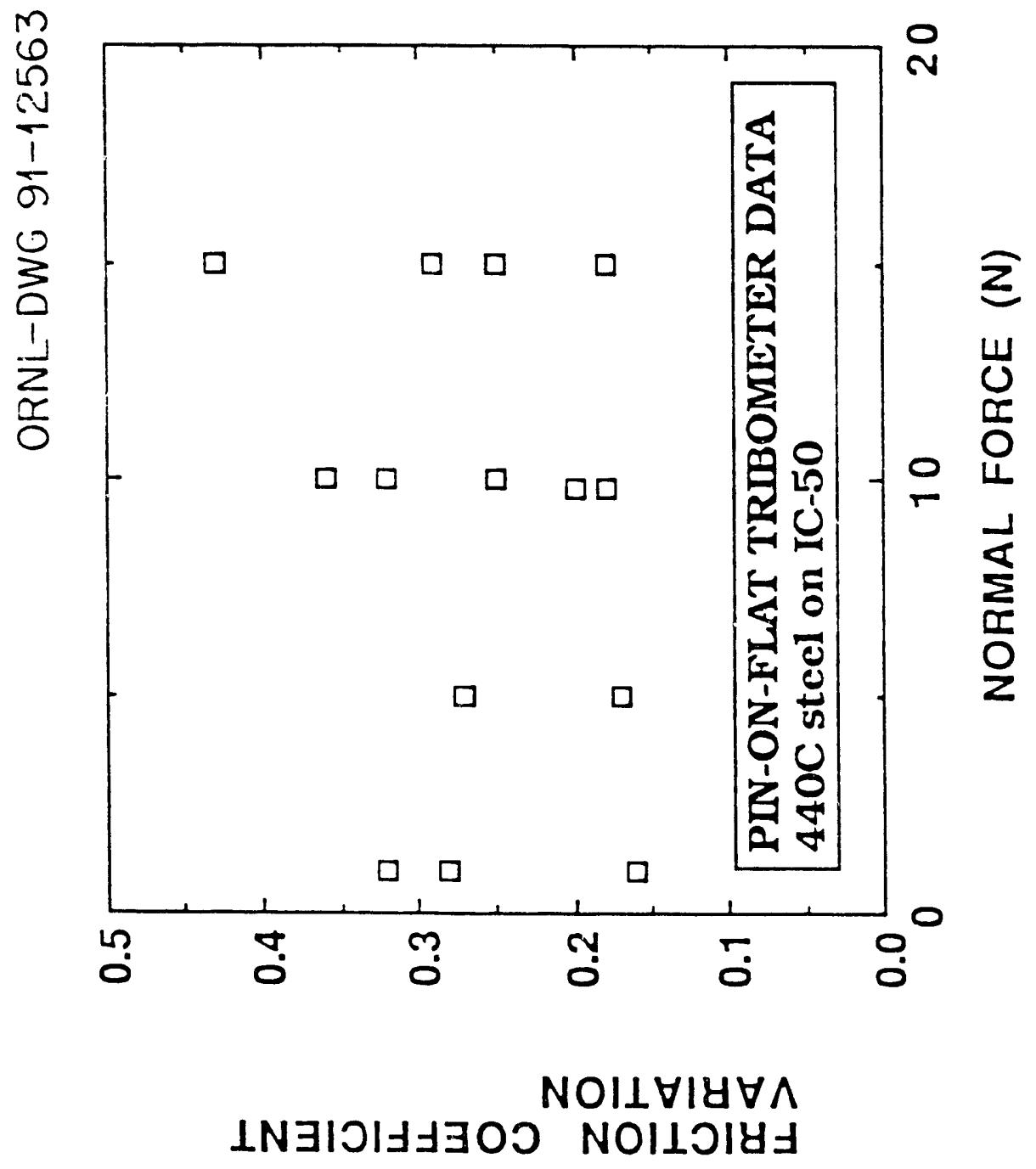

Fig 7(b) 


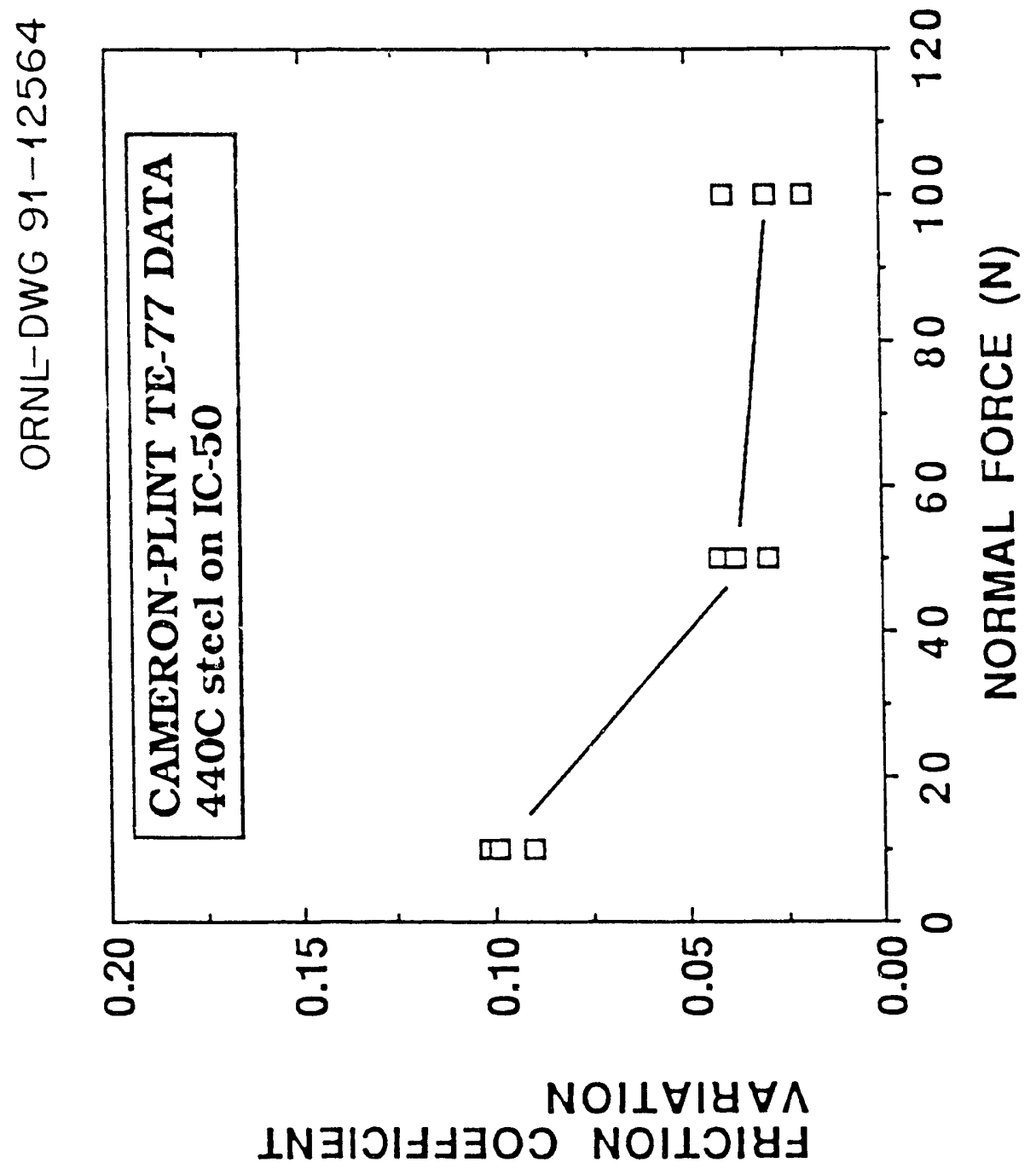

Fig $7(c)$ 


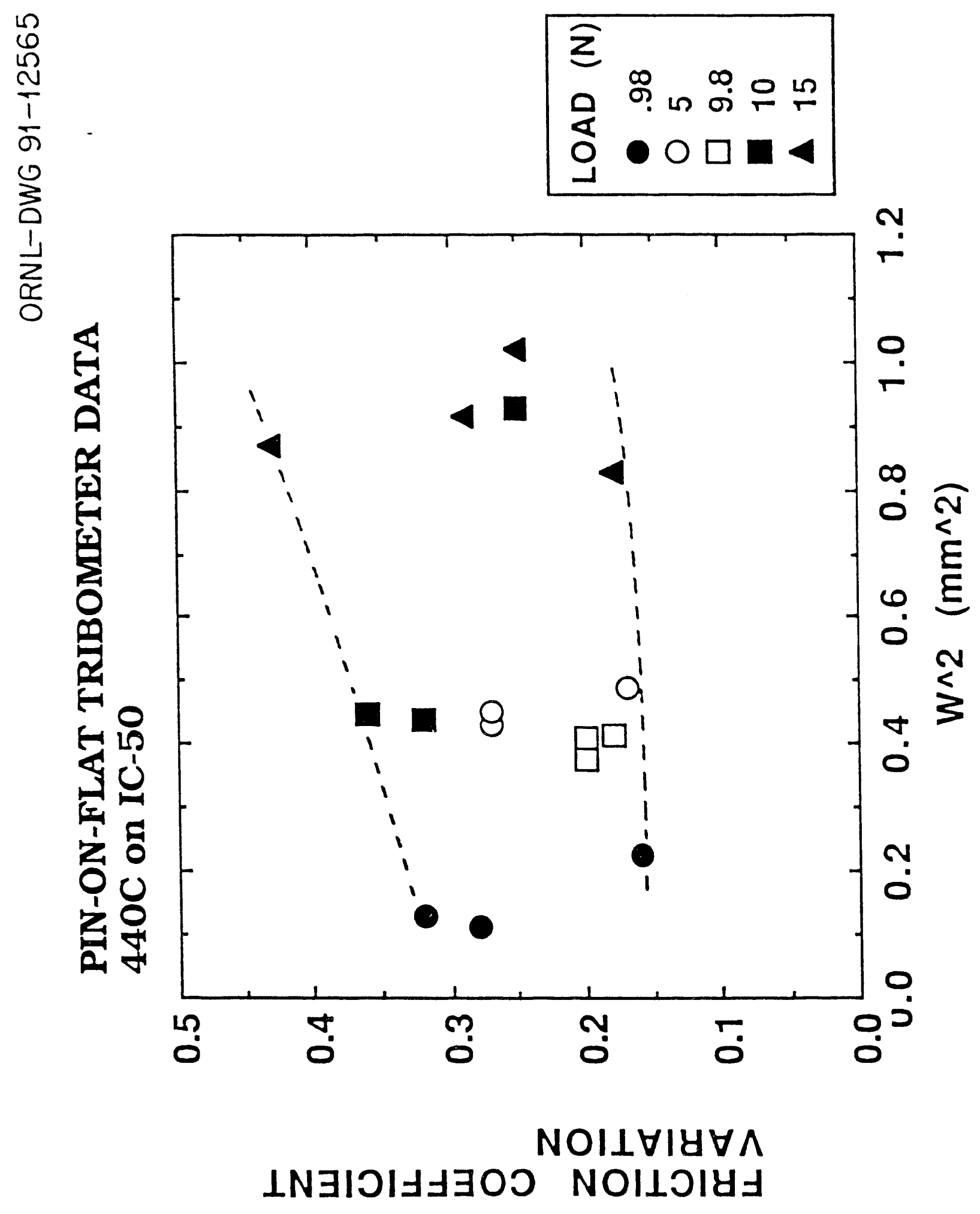

Fig. $8(a)$ 


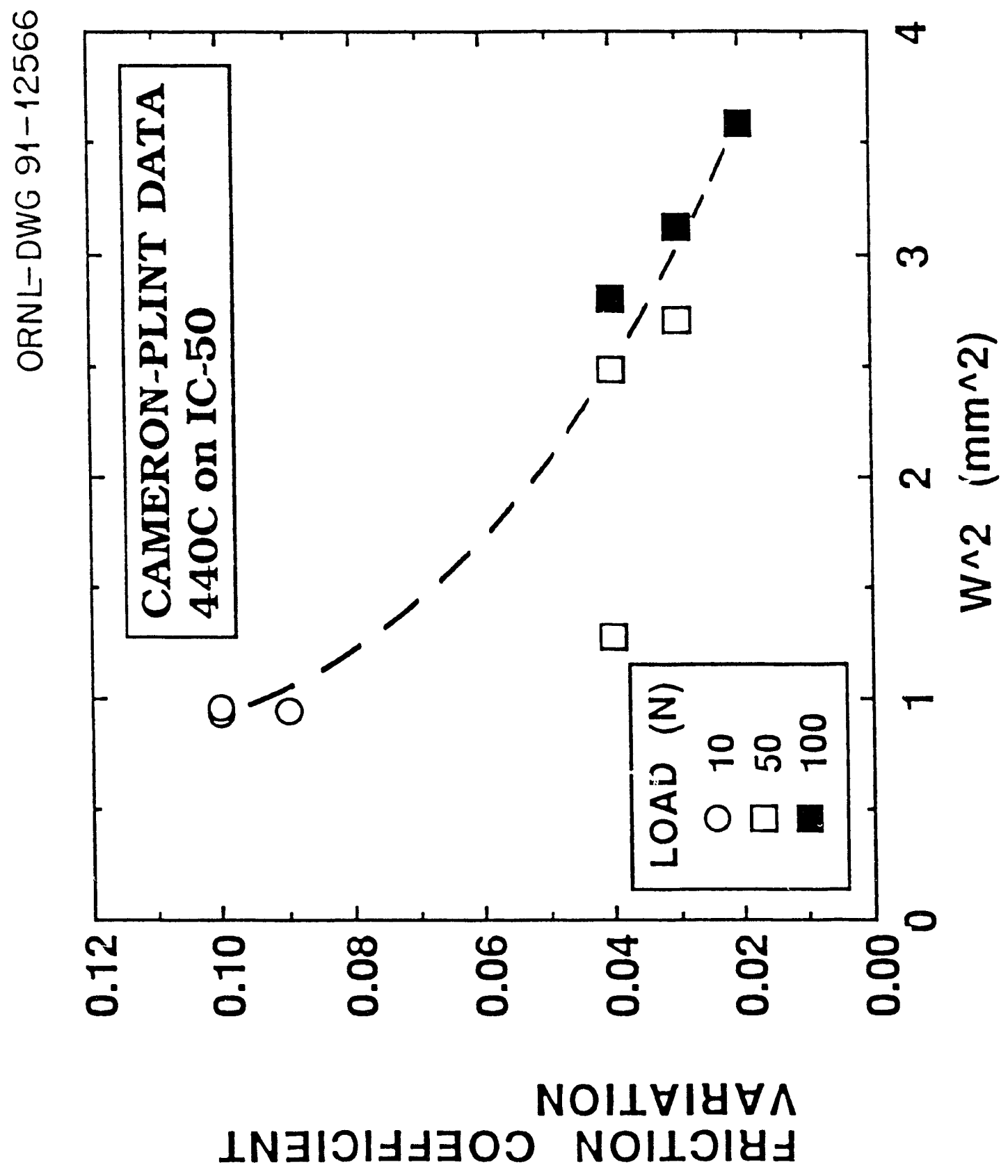

$F_{i g} g(b)$ 

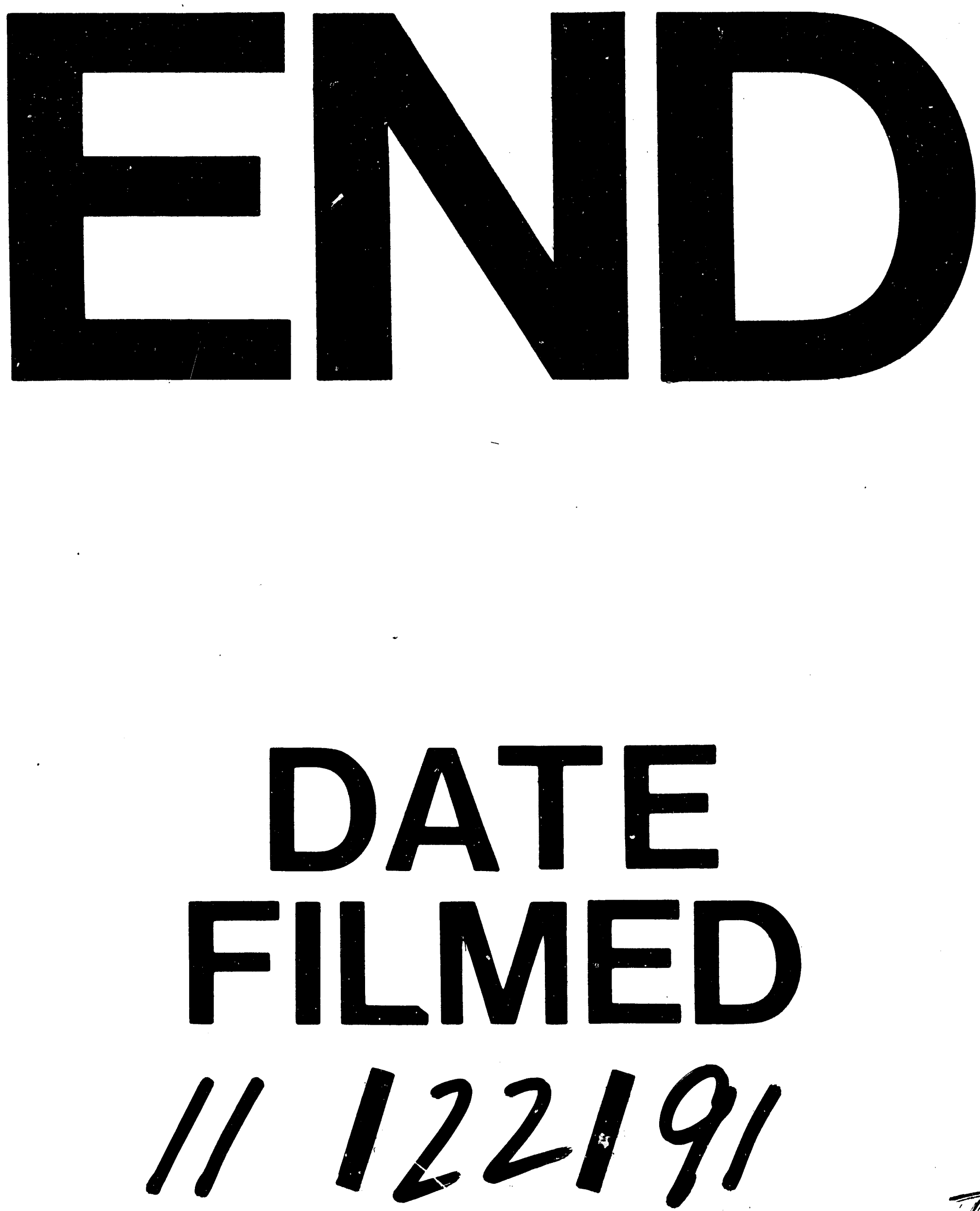
